\title{
COMUNICAÇÃO
}

\section{FREQÜÊNCIA DE ANTICORPOS CONTRA OS VESICULOVÍRUS E AFTOVÍRUS, EM BOVINOS E EQÜÍDEOS, DE CATOLÂNDIA-BAHIA}

\author{
José Tavares-Neto, Magnus S. Söndahl, Guilherme Ferreira de Oliveira, \\ Samir Farah, Paulo Severo B. Cortes, Carlos Augusto F. Molina, \\ Domingos Cassis Neto, Frederico A. S. Freitas, Guilherme R. Silva, \\ Jussara Gonçalves, Raquel M. Gonçalves, Valéria Cardoso Alves, \\ Vinicius Nahime de Brito e Waldir Facure Júnior
}

Os vesiculovírus (Família: Rhabdoviridae) e os aftovírus (Família: Picornaviridae) são agentes infreqüentes de doença clínica no homem'. Os primeiros, porque causam doença semelhante à influenza, de curta duração e difícil diagnóstico clínico-laboratorial. No entanto, a transmissão é freqüente em técnicos de laboratório de Virologia e, aproximadamente, metade dos infectados desenvolve doença clínica ${ }^{10}$; também entre os profissionais com atividades vinculadas ao manejo ou abate de animais ${ }^{8}$ esta infecção é prevalente.

De outro modo, os aftovírus, agentes da febre aftosa, causam também doença ocupacional apesar de rara ${ }^{14}$. Todavia, a freqüência aparentemente alta, na clínica pediátrica e médica deve-se à conseqüência da ampla sinonímia das $\operatorname{aftas}^{11}$ ou confusão diagnóstica com a síndrome mãos-pés-boca causada pelo vírus Coxsackie tipo $\mathrm{A}^{13}$.

Outros vesiculovírus, como o Piry, são de importancia médica no Brasil15. Os vesiculovírus New Jersey e Indiana-1 não foram isolados no Brasil'. No entranto, Andrade ${ }^{2}$ observou anticorpos contra estes dois vírus em humanos e animais, de vários Estados brasileiros.

Os vesiculovírus e os aftovírus têm grande importância econômica na pecuária por comprometerem a produção de leite e carne ${ }^{3}{ }^{4}$. Os

\footnotetext{
Trabalho da Faculdade de Medicina do Triângulo Mineiro, Uberaba/MG

Endereço para correspondência: Dr. José TavaresNeto, R. Marquês de Caravelas 262/101, 40160 Salvador, BA.

Recebido para publicação em 14/03/91.
}

bovídeos e eqüídeos são susceptf́veis aos vesiculovírus; entretanto, os eqüídeos são resistentes à febre aftosa, sendo essa característica importante no diagnóstico clínico diferencial durante epizootias.

No município de Catolândia, localizado na região oeste do Estado da Bahia, está em andamento projeto sobre a epidemiologia das vesiculoviroses em humanos. Em levantamento prelimar (J TavaresNeto, APA Travassos da Rosa: dados não publicados) de 57 indivíduos adultos (média da idade de 32,7 $\pm 13,5$ e limites de 18 a 71 anos), de ambos os sexos (28 do sexo masculino), selecionados por sorteio e testados os soros através da prova de vírus neutralização ${ }^{16}$, usando a técnica do soroconstante em camundongos recém-nascidos, os anticorpos contra os vesiculovírus Cocal, Carajás e Marabá não foram observados. Dois casos $(3,5 \%)$ foram positivos para o VSV-3 (Alagoas); um deles, também, foi positivo para o Piry. A freqüência de anticorpos contra o vírus Piry foi de $33,3 \%(n=19)$.

Pretendeu-se fazer o levantamento de anticorpos contra alguns vesiculovírus e cepas do aftovírus em animais adultos bovinos (vacas leiteiras) e eqüídeos (eqüínos, muares e asininos), de ambos os sexos do município de Catolândia-Bahia. As amostras de sangue, da veia jugular, foram coletadas em papel de filtro (Klabin 80) entre os dias 12-26 de janeiro de 1990. Os animais estavam igualmente distribuídos na área do município e a seleção da propriedade agrícola foi feita através de sorteio $(n=42)$. Nesse caso, até três vacas leiteiras foram escolhidas ao acaso e todos os eqüídeos da propriedade foram testados. No censo agropecuário de $1980,49,5 \%(n=319)$ dos estabelecimentos agrícolas tinham menos de 10 hectares $^{9} \mathrm{e}$ a média de vacas por propriedade era de $2,1^{9}$. 
Comunicação. Tavares-Neto J, Söndahl MS, Oliveira GF, Farah S, Cortes PSB, Molina CAF, Cassis-Neto D, Freitas FAS, Silva GR, Gonçalves J, Gonçalves RM, Alves VC, Brito VN, Facure Jr W. Frequiência de anticorpos contra os vesiculovírus e aftovírus, em bovinos e eqüideos, de Catolândia-Bahia. Revisia da Sociedade Brasileira de Medicina Tropical 24:177-179, jul-set, 1991

A prova de vírus neutralização em microplacas, com células IB-RS-2 clone $17^{\circ}$, foi usada no levantamento sorológico ${ }^{16}$. Os resultados para febre aftosa foram obtidos frente às três cepas de referência para o Brasil: $\mathrm{O} 1$ (Campos-Br 1/58), A24 (Cruzeiro-Br 1/55) e C3 (Indaial-Br 1/71). Para a estomatite vesicular foram utilizadas as cepas Indiana - 2 (Ribeirão - Br/79) e Indiana - 3 (Alagoas - Br/64). Soros controles positivos e negativos foram também usados. Os testes foram realizados no Centro Panamericano de Febre Aftosa (Rio de Janeiro) e observando-se as normas técnicas padronizadas'.

Os resultados qualitativos dos 214 animais (78 bovinos e 136 eqüídeos) estão dispostos na Tabela 1. Foram considerados positivos todos aqueles com títulos maior ou igual a $10^{1}{ }^{3}$ DI50 $\mathrm{MT} / \mathrm{ml}$ (diluição final $=1 / 20)^{6}$. Os percentuais referentes à presença dos anticorpos neutralizantes contra cada cepa foram extraídos do total de animais porque, muitas vezes, o mesmo animal apresentou anticorpos para mais de uma cepa e alguns contra as três (no caso dos aftovírus). Somente um bovino teve anticorpos neutralizantes anti-Ribeirão (VSV-2) e anti-Alagoas (VSV-3). Entre os equiídeos, os dois com anticorpos antiVSV2 tinham também anti-VSV3. No caso de anticorpos neutralizantes para mais de uma cepa do vírus da febre aftosa a distribuição era a seguinte: 4 bovinos apresentaram anti-01 e antiA24, 6 anti-01 eanti-C3 e 11 animais contra as três cepas.

A importância da estomatite vesicular parece ser relevante em Catolândia, principalmente devido à freqüência de anticorpos neutralizantes anti-VSV3 (Alagoas) observada nos eqüídeos $(50,0 \%)$. Do mesmo modo que nos bovinos, a febre aftosa tem grande importância $(48,7 \%)$. Para os animais con anticorpos anti-aftovínus, porém, os resultados sorológicos expressam, também, a eventual cobertura vacinals ${ }^{5}$. Segundo as informações dos criadores locais, a vacinação é irregular e esporádica. Não se encontraram informações atuais, nem dos últimos dez anos, na região do município de Catolândia sobre a vacinação anti-aftosa e os tipos das vacinas utilizados.

Em recente levantamento (julho/1990), através de entrevistas da população do município (J Tavares-Neto: dados não publicados) foi freqüente o conhecimento popular de aftosa em bovinos, eqüídeos e suínos. Somente $2(0,2 \%)$ pessoas com 12 anos ou mais de idade $(n=325)$ reconheciam a febre aftosa (conhecida na região como gambarra, em lugar de gabarro, como é referida a deformação podal em outras regiões do Brasil) como doença característica apenas dos

Tabela 1 - Freqüencia dos anticorpos neutralizantes contra os vesiculovirus e os aftovírus, em bovinos e eqüideos de Catolándia - Bahia

Anticorpos neutralizantes $n(\%)$

Virus

Cepa

Bovinos $(n=78)$

Eqüídeos $(n=136)$

Febre aftosa

$\begin{array}{cc}\text { O1 } & 35(44,9) \\ \text { A } 24 & 17(21,8) \\ \mathrm{C}_{3} & 19(24,4) \\ \text { Total }+ & 38(48,7) \\ \text { Negativos } & 40(51,3)\end{array}$

Estomatite

VSV-2

VSV-3

Total +

Negativos
$2(2,6)$

$2(2,6)$

$3(3,8)$

$75(96,2)$
$2(1,5)$

$68(50,0)$

$68(50,0)$

$68(50,0)$ 
Comunicação. Tavares-Neto J, Söndahl MS, Oliveira GF, Farah S, Cortes PSB, Molina CAF, Cassis-Neto D, Freitas FAS, Silva GR, Gonçalves $J$, Gonçalves RM, Alves VC, Brito VN, Facure Jr W. Freqüência de anticorpos contra os vesiculovirus e aftovirus, em bovinos e eqüideos, de Catolândia-Bahia. Revista da Sociedade Brasileira de Medicina Tropical 24:177-179, jul-set, 1991

bovinos e suínos. Portanto, parece ser comum a observação da estomatite vesicular entre os eqüídeos, principalmente pelas pessoas maiores de 30 anos de idade; também, o relato da observação recente de doença vesicular foi freqüente. Contudo, na região oeste da Bahia os casos notificados são ocasionais e não há informação precisa para o município de Catolândia ${ }^{12}$.

Este é o primeiro estudo sorológico sistematizado nesta região do Estado da Bahia, inclusive para os vesiculovírus.

\section{REFERÊNCIAS BIBLIOGRÁFICAS}

1. Acha PN, Szyfres B. Zoonosis y enfermedades transmisibles comunes al hombre y a los animales. Organización Panamericana de la Salud, 2a. edição, publicação científica $\mathrm{n}^{\circ}$ 503, Washington, 1986.

2. Andrade CM. Estomatite vesicular no Brasil. Tese de Docência Livre, Universidade Federal do Rio de Janeiro, 1974.

3. Astudillo VM, Estupiñán J, Rosenberg FJ, Silva AJM, Dora JFP, Urbina M, Tamayo H, Lora JQ, Marrero JC. Estudo epidemiológico de la Estomatitis vesicular en America del Sur. Descripcion de los datos del sistema continental de vigilância de enfermedades vesiculares. Centro Panamericano de Fiebre Aftosa. Organización Panamericana de la Salud, Serie de Monografias y Técnicas no $15,1986$.

4. Callis JJ, Dardiri AH, Ferris DH, Gay J, Wilder FW, Mason J. Manual ilustrado para el reconocimiento y diagnostico de ciertas enfermedades de los animales. Comissión MexicoAmericana para la Prevencion de la Fiebre Aftosa, Plum Island, 1982.

5. Fenner F, Bachmann PA, Gibbs EPJ, Murphy FA, Studdert MJ, White DO. Veterinary Virology. Academic Press Inc, Orlando, 1987

6. Fernández AA. Manual de diagnóstico de laboratório de las enfermedades vesiculares. Centro Panamericano de Fiebre Aftosa/Organización Panamericana de la Salud, Serie de manuales didacticos $n^{\circ} 15,1986$.

7. Fernández PG. Application of monoclonal antibodies in indirect immunofluorescence for diagnostic subtyping of vesicular stomatitis (Indiana serotype). Master thesis, Yale University, 1988.

8. Hanssen H, Zuluaga FN, Hanssen G. Evidencia sorologica da estomatitis vesicular en empleados de matadero, Antioquia, Colombia. Boletin de la Oficina Sanitaria Panamericana 86:141-147, 1979.

9. Instituto Brasileiro de Geografia e Estatísitea (IBGE). Censo agropecuário 1980/Bahia. Fundação Instituto Brasileiro de Geografia e Estatística tomo 3, 1a. parte, volume 2, 1983.

10. Johnson KM, Vogel JE, Peralta PH. Clinical and serological response to laboratory-acquired human infection by Indiana type vesicular stomatitis virus (VSV). The American Journal of Tropical Medicine and Hygiene 15:244-246, 1966.

11. Leite AG. Aftas bucais. Editora de Publicações Médicas, 4a. edição. Rio de Janeiro, 1988.

12. Ministério de Agricultura. Relatório de luta contra a febre aftosa. Ministério de Agricultura, Brasil. Brasília, mimeografado, 1989.

13. Minkoff DI, Connor JD. Hand-foot-mouth disease. $I n$ : Braude AI, Davis CE, Fierer $\mathbf{J}$ (ed) Infectious diseases and medical microbiology, 2a. edição, WB Saunders Company, Philadelphia p.1436$1437,1986$.

14. Santa Rosa CA. Febre aftosa. In: Veronesi R (ed) Doenças Infecciosas e Parasitárias. 7a. edição. Editora Guanabara Koogan, Rio de Janeiro p.205207, 1983.

15. Tavares-Neto J, Travassos da Rosa APA, Ataide M, Morais-Souza H, Vasconcelos P, Travassos da Rosa J. Freqüência de anticorpos neutralizantes contra o vesicoluvírus Piry, em doadores de sangue de Uberaba, Minas Gerais, Brasil. Revista do Instituto Medicina Tropical de São Paulo 32:211214, 1990.

16. Theiler $M$, Downs WG. Investigation test studies. In: Theiler $\mathrm{M}$ (ed) The arthropod-borne viruses of vertebrates. Minor groups of arbovirus, 1a. edição, Yale University Press, New Haven p.3-35, 1973. 